\title{
Placental site trophoblastic tumor with perimetrial invasion and cesarean scar perforation (A case report)
}

\author{
Geeta Gurung, Archana Amatya, Nupur Thakur, Ashma Rana \\ Dept of Gyn/Obs, TU Teaching Hospital
}

\begin{abstract}
Placental site trophoblastic tumor (PSTT) a rare variety of gestational trophobalstic neoplasia described in younger women, usually following term delivery characterized by low serum B hCG level was met in a 32 year old lactating mother, who resumed normal menstruation after three months of cesarean section up to three cycles followed by amenorrhea for eight months; evacuation for presumed missed abortion prompted the diagnosis of PSTT which at the time of hysterectomy was found invading perimetrium and perforating the uterine cesarean scar.

Conclusion: Careful evaluation of lactational amenorrhea is indicated so that the diagnosis of PSST may not be missed in the background of elusive picture such as missed abortion with low serum $B$ hCG, histological examination of the evacuated material may be relied which may provide the diagnosis at times.
\end{abstract}

Key words: Placental site trophoblastic tumour (PSTT), hysterectomy, low serum B hCG

\section{Introduction}

Placental site trophoblastic tumor (PSTT) is the rare variety of gestational trophoblastic disease constituting about $1-2 \%$ of all trophoblastic tumors. ${ }^{1-3}$ Approximately only 150 cases have been recorded in the literature till date. But perforating PSTT with perimetrial invasion is hardly reported in literature which this case study aims to illustrate. ${ }^{4}$

\section{Case}

A 32 years old multipara $\mathrm{P}_{2+3}$ with history of 3 abortions (on $1^{\text {st }} 2^{\text {nd }}$ and $4^{\text {th }}$ order of birth) and 2 cesarean (former for breech and the last one, $1 \frac{1}{2} 2$ years back for placenta previa), who was breast feeding had resumed normal menstrual period three months post partum for three consecutive regular cycles was worried because of eight months of amenorrhea and urine that tested positive for pregnancy.
During examination, there was uterine enlargement to 10 weeks pregnancy size and the ultrasonogram suggested missed abortion. She was subjected for suction and evacuation and the minimal amount of tissue obtained sent for histopathological examination gave the possibility of PSTT. The patient party reluctant for surgery, serial serum $\beta \mathrm{hCG}$ assay done consecutively for three months (July, August and September 2006) was reported $578.4 \mathrm{mIU} / \mathrm{ml}, 331.6 \mathrm{mIU} /$ $\mathrm{ml}$ and $436.4 \mathrm{mIU} / \mathrm{ml}$ respectively. As there was persistence of serum $B \mathrm{hCG}$, finally she gave consent for surgery and was admitted in the Department of Obstetrics and Gynecology, TU Teaching Hospital in October 2006. A CT scan done preoperatively showed bulky uterus with empty endometrial cavity.

On opening the abdomen the uterus was enlarged to 12 wks size with irregular surfaces and felt soft. There were blue hemorrhagic patches on the left cornu and on the right side of anterior surface of body of uterus (Fig 1). Isthmic area overlying the previous cesarean

Correspondence

Geeta Gurung. FCPS

Assoc Prof. Dept of Gyn/Obs, TU Teaching Hospital, IOM, Kath, Nepal

PO Box 1614, Kathmandu, Nepal.

Email: gurunggeeta@hotmail.com 
section scar was thinned out at one point showing a small perforation (fig 2). But bilateral ovaries and tubes were normal. Total abdominal hysterectomy was performed. On cut section of the uterus a $6 \times 8 \mathrm{cms}$ tumor (fig 3) was seen on the anterior surface of body of uterus which was diffuse, friable and haemorrhagic.

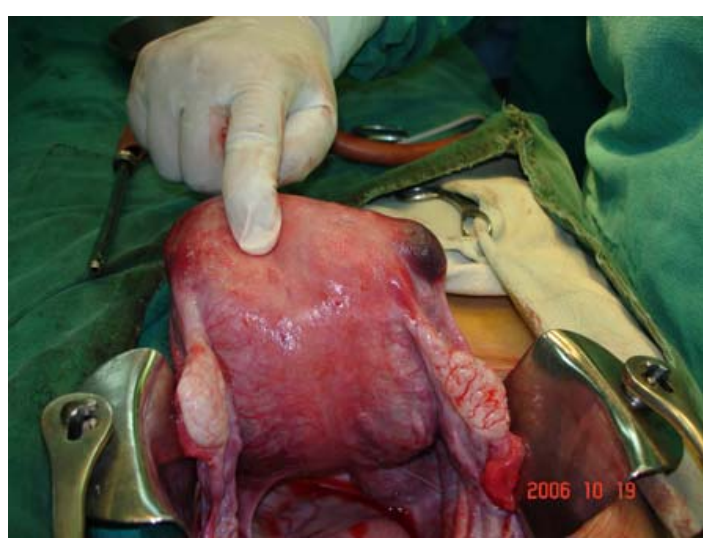

Fig I. Intraoperative picture showing hemorrhagic patches on the left cornu and on the right side of anterior surface of body of uterus.

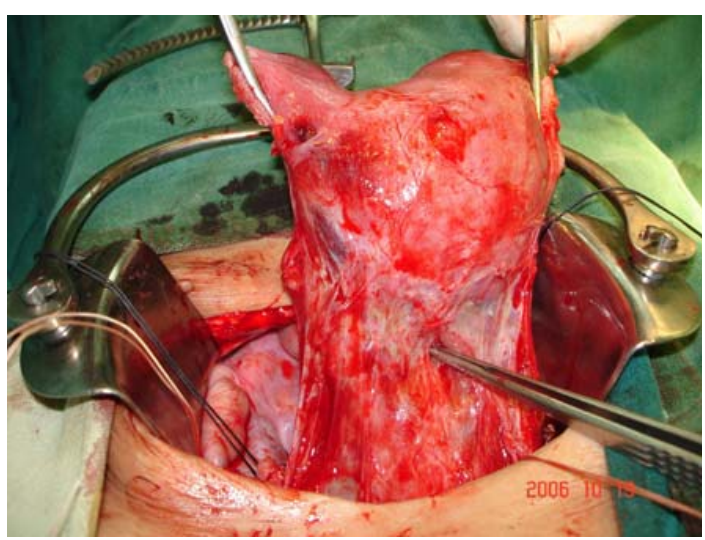

Fig 2. Thinned out previous caesarean section scar at one point overlying isthmic area, with small perforation.

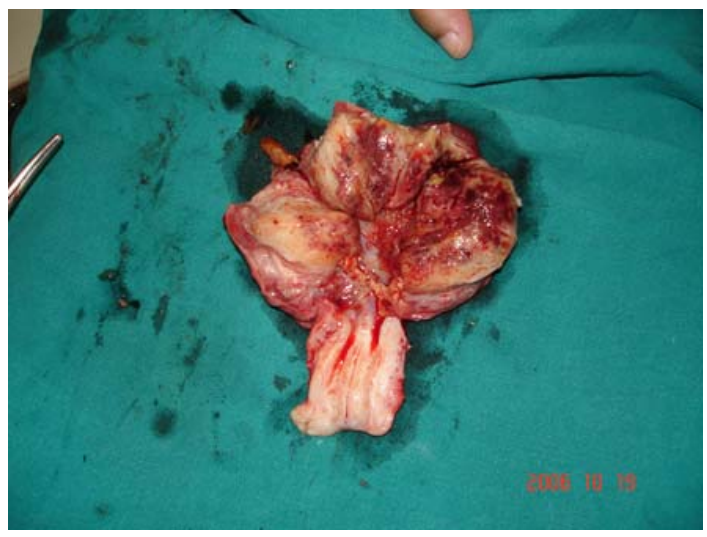

Fig 3. Cut section of the uterus.
The histopathological report revealed placental site trophoblastic tumour infiltrating up to the perimetrium. $\beta \mathrm{hCG}$ on the $7^{\text {th }}$ post operative day was $106 \mathrm{~m} \mathrm{IU/ml}$. Stitches were removed on $7^{\text {th }}$ post operative day and the patient was discharged on $8^{\text {th }}$ day with instruction for regular follow up of serum â hCG weekly which has almost come to nil subsequently after 4 weeks.

\section{Comment}

In this case, all characteristics of PSTT were present, like diagnosis at an early reproductive age 31-33, following term pregnancy, diseases confined to the uterus and low $\beta$ hCG level. ${ }^{1-3}$ The level of $\beta-h C G$, pathognomic of PSST is due to the proliferation of intermediate trophoblastic cells which is apt to produce lower values that has helped to differentiate this from other types of gestational trophoblastic diseases. On the contrary human placental lactogen (hpl) is secreted in abundance.

While, amenorrhea a less described clinical manifestation in this case unintentionally produced delay in the diagnosis as the attentions were diverted towards lactation as a cause. One more important issue regarding this case is the unexpected histological findings suggestive of PSTT derived from the tissue obtained during the suction evacuation of uterus conducted with the provisional diagnosis of missed abortion in the first place. While in other cases diagnosis has been misguiding on endometrial biopsy which was ascertained only after hysterectomy. ${ }^{4}$

Unusually the disease can have a florid spread at the time of first diagnosis. This has happened in a case of cesarean for antepartum hemorrhage unlike our case with a benign behavior. ${ }^{5}$ However extension to the perimetrium was an interesting finding denoted by histopathology where a bluish venous pool was observed over the surface of the uterus in one of the cornu, during surgery. The small perforation on the thinned out scarred lower uterine segment has been documented also from China. ${ }^{6}$ however, ovarian conservation was possible at hysterectomy.

As the disease was localized in the uterus, chemotherapy was not given. The fall in serum $3-\mathrm{hCG}$, at the end of the first week of surgery demonstrated that PSTT do not demand chemotherapy as such.

Based on the opinion that a good prognosis can be anticipated where disease is localized within the uterus and the treatment has been iniated within 2 years of antecedent pregnancy we are hopeful in this case. ${ }^{7}$ The treatment is agreeable in consideration of her age and fertility where the uterus has been sacrificed yet preserving the ovaries for endocrine functions. 


\section{Conclusion}

A lactational amenorrhea must be well evaluated in any women of reproductive age group providing an elusive picture of missed abortion with uterine enlargement and lower serum $\mathrm{BhCG}$ level by incorporating histopathological examination lest a diagnosis of PSTT be traced correctly.

\section{References}

1. Agrawal N, Parul, Kriplani A, Vijayaraghavan M. Placental site trophoblastic tumour. Journal of Postgraduate Medicine 2002; 48(3), 211-212.

2. Bonazzi C, Urso M, Dell'Anna T, Sacco S, Buda A, Cantu MG. Placental site trophoblastic tumour:An overview. J Reprod Med 2004 Aug; 49 (8):585-8.

3. Kim SJ. Placental site trophoblastic tumour. Best Pract Res Clin Obstet Gynaecol 2003 Dec; 17 (6): 969-84.
4. Moore-Maxwell CA, Robboy SJ. Placental site trophoblastic tumor arising from antecedent molar pregnancy. Gynecol Oncol 2004 Feb; 92(2):708-12.

5. Hopkins MP, Drescher CW, McQuillan A, Keyser J, Schmidt R. Malignant placental site trophoblastic tumor associated with placental abruption, fetal distress, and elevated CA-125. Gynecol Oncol 1992 Nov; 47(2):267-7

6. Lin HW, Shieh CS, Chen LM, Yang YT, Han CP Spontaneous uterine perforation mimicking ectopic pregnancy as the initial presentation of placental site trophoblastic tumor. Zhonghua Yi Xue Za Zhi (Taipei) 2001 Sep; 64(9):545-50.

7. Hassadia A, Gillespie A, Tidy J, Everard R G N J, Wells M, Coleman R, Hancock B Placental site trophoblastic tumour: clinical features and management. Gynecol Oncol 2005 Dec; 99(3): 603-7. 